\title{
Improvement of Walking Analysis using the Sciatic Function Index for Sciatic Nerve Function in Injured Rat Model Treated with Low-Intensity Aerobics
}

\author{
Ria Margiana* (iD), Kamila Alawiyah ${ }^{1}$, Khoirul Ima² ${ }^{1}$, Rizni Fitriana² ${ }^{2}$, Arif Rahmat Widodo² \\ Theresa Devi Wibowo ${ }^{2}$ D
}

${ }^{1}$ Departement of Anatomy, Faculty of Medicine, Universitas Indonesia, Jakarta, Salemba, Indonesia; ${ }^{2}$ Master's Programme in Biomedical Sciences, Faculty of Medicine, Universitas Indonesia, Jakarta, Indonesia

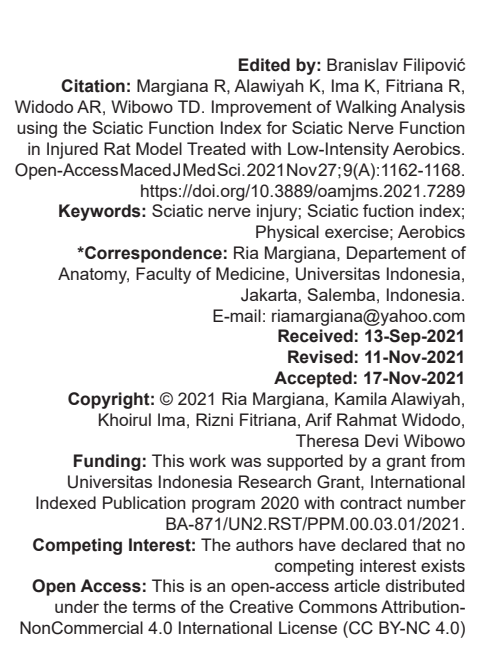

\section{Introduction}

Peripheral nerve injury occurs in the working population. These injuries can cause pain for 1 year or more [1], [2]. Movement and posture originate from muscle movement, which is controlled by the nervous system [3]. Damage to the peripheral nervous system (PNS) will affect movement control [4]. Peripheral nerve injury can cause long-term health problems. Peripheral nerve injury is a condition in which the PNS experiences a disorder or disability that causes pain in one pelvis or both to the legs [5]. This pain comes from the sciatic nerve, which is a continuation of the L4-S3 in the plexus lumbosacral [6]. Pathophysiological conditions of sciatica are pathological conditions that can occur in the intervertebral disc and the sciatic nerve itself. Several factors that can influence this disease include gender, posture, age, genetic factors, and occupation. In addition, the causes of peripheral nerve injury can vary an example of disc herniation, causing direct compression and an inflammatory reaction to the nerve roots on the inside of the spinal canal. Nerve compression and irritation can cause sensations of pain, numbness or numbness, tingling, and muscle weakness [7]. Various methods and healing therapies have been carried out. One of them is standard therapy with surgery. However, the results of standard therapy with surgery result in an unsatisfactory condition [8], [9]. In addition, standard therapy with surgery also requires quite a lot of money. Therefore, research is needed on effective healing therapy in cases of peripheral nerve injury, one of which is using physical exercise therapy with aerobics. Studies show that low-intensity aerobic 
exercise can induce the production of neurotrophic synthesis factors that stimulate nerve growth [10], [11].

Unlike injuries to the central nervous system, when axons in the PNS are injured, there is a strong regenerative response resulting in good functional repair in distal nerve lesions. In contrast to proximal nerve lesions, some will have poor recovery due to slower regeneration rates and chronic denervation changes occurring in the distal nerve segments and target muscles [12]. Various strategies that can promote axonal growth will have beneficial effects on regeneration peripheral nerves. The role of growth factor in one of the neurotrophin protein families, namely, Nerve Growth Factor (NGF) in the Ras/ Raf/ERK pathway according to some literature is related to cell cycle regulation and development of neural phenotype, while transient ERK activation is associated with proliferation. The Ras/Raf/ERK pathway itself has a function to regulate differentiation and other physiological functions in several cell types including Schwann cells [11]. Complete recovery after injury to the PNS is rare. This can be caused by three reasons. The first is because the regeneration of the axons is slow and not all axons participate in regeneration. Second, due to the wrong direction of axon regeneration. And finally, there are permanent changes in neural circuits in the central nervous system which were found to accompany the axotomy of peripheral axons [10]. Exercise has indeed been shown to increase neurite growth in dorsal root ganglion neurons carried out in experimental animals in the acute period [11]. Peripheral nerve regeneration is the ability of peripheral nerves to repair themselves, this includes reestablishing functional connections, which can last for months or even years. This regeneration process is critical for the functional continuation of nerves after injury [13]. The extent of nerve regeneration can depend on the severity of the nerve injury, the time at which it is innervated, and the condition of the peripheral nerve tissue itself. However, the complex process of degeneration and regeneration of peripheral nerves is not fully understood [14]. To find out the functional damage caused by the presence of this nerve lesion (peripheral nerve injury), it is necessary to analyze the movement that is considered to represent the characteristics of the nerve damage [15]. Movement analysis used as a parameter of nerve damage can be in the form of SFI [16]. A study conducted by Tajino et al. who said that there are still shortcomings in motion analysis that does not include the use of systematic, standardized, and reliable methods so that it becomes an obstacle to the wider application of animal analysis [17].

Various studies that have been carried out in terms of nerve regeneration have only focused on morphological aspects so that evidence that morphological regeneration results in functional recovery is still lacking [18]. Some of the studies used the sciatic functional index (SFI) method to evaluate hindlimb function in sciatic nerve injury and nerve regeneration in rats [19], [20], [21]. The development of modification of the SFI method requires the measurement of three parameters in the prints of the hind paws of rat, which are incorporated into a specific mathematical formula. SFI is a negative indicator of the degree of nerve dysfunction varying from 0 to 100 , with 0 indicating normal function and 100 indicating total dysfunction. SFI is directly correlated with nerve fiber density and is a reliable method of evaluating functional deficiency of the sciatic nerve in rats [18], [19], [22]. Although SFI can be used as a functional indicator of sciatic nerve regeneration, studies leading to the analysis of gait after low-intensity treadmill treatment have not yet been found. The human genome encodes 21 members of the $\mathrm{S} 100$ protein family, which exhibits cell and tissue-specific expression patterns [19], [23]. Despite sharing high-order sequences and structural similarities, S100 proteins bind to a variety of protein targets and contribute to the measurement of various intracellular and extracellular functions. Therefore, the S100 protein regulates various cellular processes such as proliferation, migration and/or invasion, and differentiation, and also has an important role in various diseases such as cancer, autoimmune diseases, and chronic inflammatory disorders [24]. Park and Hoke (2014) reported that daily exercise has an important role in peripheral nerve regeneration [25]. However, research in molecular aspects and gait analysis in rats regarding the role of low-intensity treadmill exercise on the effect of S100 protein expression is still unknown. Hence, the theme of this research is still very open for further study. The purpose of this study was to determine the effect of giving aerobic exercise after treatment of peripheral nerve injury and to determine its relationship to walking function during injury-induced peripheral nerve regeneration.

\section{Methods}

\section{Place and time of research}

The research was conducted at the Animal House Research and Development Ministry of Health, Department of Histology, Faculty of Medicine, Laboratory of Developmental Biology, and the integration laboratory of anatomical biology and histology, University of Indonesia, Indonesia.

\section{Research code of ethics}

This research will be conducted after an ethical review by the Health Research Ethics Committee, Faculty of Medicine, University of Indonesia, and obtaining a certificate of passing the ethical review, July 27, 2020, No. protocol 19-07-0852. 


\section{Animal subject}

This research is experimental analytical laboratory research on male Sprague-Dawley rats with an age of about 2-3 months. The number of rats used was 18 with three groups of six in each group. The first group is a control group that has a code $\mathrm{K}$, was treated in the form of surgery without clamping/injuring the peripheral nerves. The second group was the group that was given the treatment of peripheral nerve clamping/injury and the treatment of physical exercise with aerobics which had code P1. The third group is the group that is given the treatment of peripheral nerve clamping/injury and not given the treatment of physical exercise with aerobics which has code P2. The method of making a model of peripheral nerve injury is done by clamping the sciatic nerve using a surgical clamp. Clamping on the sciatic nerve was performed for $3 \mathrm{~min}$.

There are three treatment groups, the minimum sample that must be owned is more than or equal to 8.5 rat. The value is rounded to 9 for ease of calculation. Here is the calculation:

$$
\begin{aligned}
& (t-1)(r-1) \geq 15 \\
& (3-1)(r-1) \geq 15 \\
& 2(r-1) \geq 15 \\
& r \geq 8,5
\end{aligned}
$$

Information:

- $r=$ Number of replications (sample size)

- $\mathrm{t}=$ Number of treatment groups

The number of samples is entered again into the Mead formula where the values must range from 10 to 20 so that the data obtained are significant. It was found that nine tails did not produce a significant amount. Therefore, the value of $E$ was determined to be 15 to get more significant results. Here is the calculation:

$$
\mathrm{E}=\mathrm{N}-\mathrm{T}
$$

$15=\mathrm{N}-3$

$\mathrm{N}=18$

Information:

- $\mathrm{E}=$ Freedom

- $\mathrm{N}=$ Number of samples used in the study

- $\mathrm{T}=$ Number of treatment groups

The calculation resulted in a value of $n=18$, so the number of rat used was 18 . This is following the FKUI Ethics Committee regarding the use of rats in each experimental group, namely, 4-6 rats. This study used 18 rats with six rats as per group.

\section{Nerve functional repair analysis with SFI}

Nerve functional evaluation was carried out using the SFImethod. The purpose of the SFI test is to evaluate the nerve function and gait of the rat so that it can be confirmed that the rat has suffered a peripheral nerve injury/sciatica. Therefore, the SFI test can be an indicator of inclusion criteria. In addition, SFI could also analyze healing in the gait pattern of rats after being given peripheral nerve injury. SFI was carried out before the peripheral nerve injury was started after the injury was given, and after being treated with aerobic physical exercise.

\section{Ischiadicus function index (SFI) measurement}

The block-shaped hallway made of acrylic is used as a place for rat to walk. Size used; width: $7.5 \mathrm{~cm}$; height: $10 \mathrm{~cm}$; length: $100 \mathrm{~cm}$. The hallway is lined with millimeter paper with a size of $10 \times 200 \mathrm{~cm}$. Rats were taken from the cage. The four paws of the rat were given different colors.

\section{Front right: Red \\ II. Front left: Black \\ III. Back right: Green \\ IV. Back left: Blue.}

Rats were directed into the hallway. Rats may walk through the hallway from the end to the bottom of the hall. The rat was returned to the cage again. Millimeter paper was taken and recorded size, the distance between the heel and third toe, print length (PL); distance from finger one to finger fifth, toe spread (TS); the distance between the second and fourth fingers, the intermediate TS. The three measurements were taken from the treated/experimental side leg $(E)$ and the normal side leg (N). SFI is calculated by the formula:

$$
\text { SFI=-38.3 (EPL-NPL/NPL)+ } 109.5 \text { (ETS-NTS/ }
$$

NTS)+ 13.3 (EITS-NITS/NITS)-8.8

A normal SFI score is around zero, while an SFI score of -100 indicates total dysfunction.

\section{Treatment of aerobic physical exercise}

Rats were treated with aerobic physical exercise after being given peripheral nerve injury. The treatment of physical exercise with aerobics is as lowintensity aerobic exercise, namely, a modified treadmill for rats. The intensity of giving physical exercise treatment with aerobic that is carried out is for 42 days. Every week it is done 4 times. The intensity of the use of the treadmill is $30 \mathrm{~min}$ with a warm-up for $5 \mathrm{~min}$, at a speed of $25 \mathrm{~m} / \mathrm{min}$. Adaptation to the treadmill was carried out before the start of the treatment. The adaptation with the treadmill was carried out for 3 days at a time of $10 \mathrm{~min}$ at a speed of $5 \mathrm{~m} / \mathrm{min}$.

Histologic staining with hematoxylin-eosin (HE) and immunohistochemistry (IHC) with growthassociated protein 43 (GAP43) and S100

Rats were sacrificed after 42 days. Parts of the peripheral nerves or the sciatic nerve were isolated to make histological and immunohistochemical preparations. The sciatic nerve was prepared after being 
serially cut crosswise with a thickness of $5 \mathrm{~m}$. Histological staining used was $\mathrm{H}$ ) staining. The immunohistochemical dyes used were rabbit GAP43 antibody (Bioss, bs-0154R) and rabbit S100 antibody (ab52642).

\section{Statistical analysis}

The data were evaluated using analysis of variance (ANOVA) and paired $t$-test with SPSS 26. The statistically tested data were the SFI data.

\section{Results and Discussion}

The method of recording and recording the footprints of the rats' upper and lower limbs (walking tract analysis) is a variable to measure the SFI value. Making this footprint can also be used to analyze the state of anatomy, physiology of the limbs, and the sciatic nerve after treatment is given. The sciatic nerve which has the Latin name nervus ischiadicus is the largest in humans with a size of approximately $2 \mathrm{~cm}$ and is a continuation of the plexus sacralis. The plexus sacralis before becoming the sciatic nerve will form a branch (rami) on the inferior side of the $m$. piriformis through the foramen ischiatic majus on the os coxae [1]. The sciatic nerve is a combination of two nerves, namely, the nervus tibialis originating from the ventral side of the plexus sacralis as high as L4 to S3 and the nervus fibularis communis originating from the dorsal side of the plexus sacralis as high as L4 to S2 [3]. However, there are differences in the origin of the sciatic nerve between humans and rats. In this study, SpragueDawley rats were used, where the origin of the sciatic nerve originates from $L 4$ to $L 5$ [4]. The sciatic nerve does not supply the gluteal area but supplies the posterior region of the thigh muscles, flexor muscles of the knee, and all muscles in the knee area to the soles of the feet. If there is a lesion or damage to the sciatic nerve, it will cause difficulty walking in a person or experimental animals, namely, rats. In the literature it is stated that the common fibular nerve in the sciatic nerve is the nerve that is most often damaged. If there is damage to the sciatic nerve, the most visible characteristics are foot drop on the soles of the feet and high-stepping gait [3]. High-stepping gait or steppage gait itself can be interpreted as an inability to lift the leg when walking because of muscle weakness causing muscle weakness. The sole becomes dorsiflexed, and a foot drop occurs [5]. In a person with a steppage gait, the knee will usually elevate the knee higher than the normal side of the foot. This serves as an attempt to lift the sole. In addition, the presence of a steppage gait makes it difficult for a person to walk on the heel due to a weakness in dorsiflexion so that a person tends to drag/pull the sole on the floor [6].

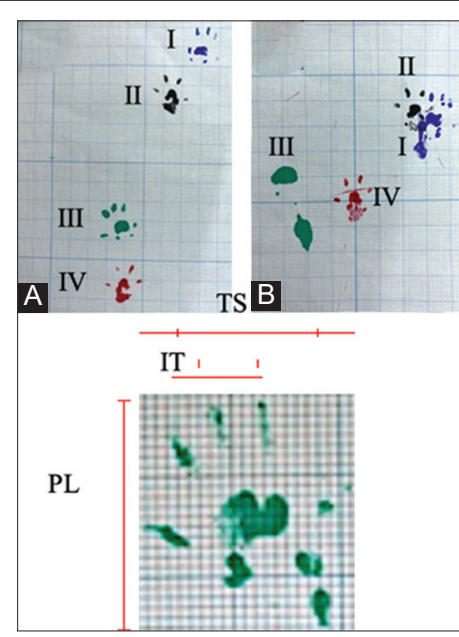

Figure 1: Representative footprint of the hindfoot without peripheral nerve injury $(A)$ and peripheral nerve injury $(B)$. The limb was treated as the left hind foot (III). I, the blue footprint for right hind foot; II, the Black footprint for right front foot; III, the green footprint for left hind foot, IV, Red footprint for the left front foot. PL-distance from heel to 3rd toe (Print Length); TS- distance from the first toe to the 5th, the width of the foot (Toe Spread); IT 2nd finger to 4th finger distance, (Intermediate Toe Spread)

The treatment in this study was to provide peripheral nerve injury, namely, the sciatic nerve in the left lower leg. The part of the leg that is treated with this injury is shown in the green toe stamp. Figure 1 shows an example of a normal leg stamp and an injured leg. This footmark shows a lot of difference. Normal toe stamps are indicated by the widening of the toe caps and the width between the toe segments, while the toe stamps between the injured toes have a shorter distance and are not visible from one finger to another due to the curved and close condition of the feet. In addition, in normal mouse footprints, the distance between the $3^{\text {rd }}$ knuckle and the heel is quite close. Meanwhile, in injured rats, the distance between the $5^{\text {th }}$ toe and the heel tended to be longer. This shows that there is a clear steppage gait in the $\mathrm{P} 1$ group, namely, the injured group rats that were given aerobic treatment. Where on the $1^{\text {st }}$ day, the results of the mouse paw print (green) have a longer experimental PL than the control group (K). The distance between each step in normal rats has a long distance, while the distance between the legs of rats treated with injury is quite short [26].

SFI analysis was carried out from day 3 to day 42. Footprints performed on day 3 and day 7 in the injured group with aerobic treatment (P1) and injuries without aerobic treatment (P2) showed a disturbance in the way they walked. However, the control group did not show any disturbance in gait (Table 1). In addition, these data are supported by SFI data, namely, in treatment $\mathrm{P} 1$, the SFI value is -144 and $\mathrm{P} 2-87$. This shows that the value is still close to the total sciatic nerve damage, which is -100 (Figure 2). The SFI result on the control group showed no significant change from day 3 to day 42 ( $p<0.05$; ANOVA). This result indicated that there was no nerve damage or repair of the sciatic nerves in the control group because the control group rat was not undergone the sciatic nerve injury. There was a 
Table 1: Changes in the overall footprint of rat limbs from day 3 to day 42 in each treatment

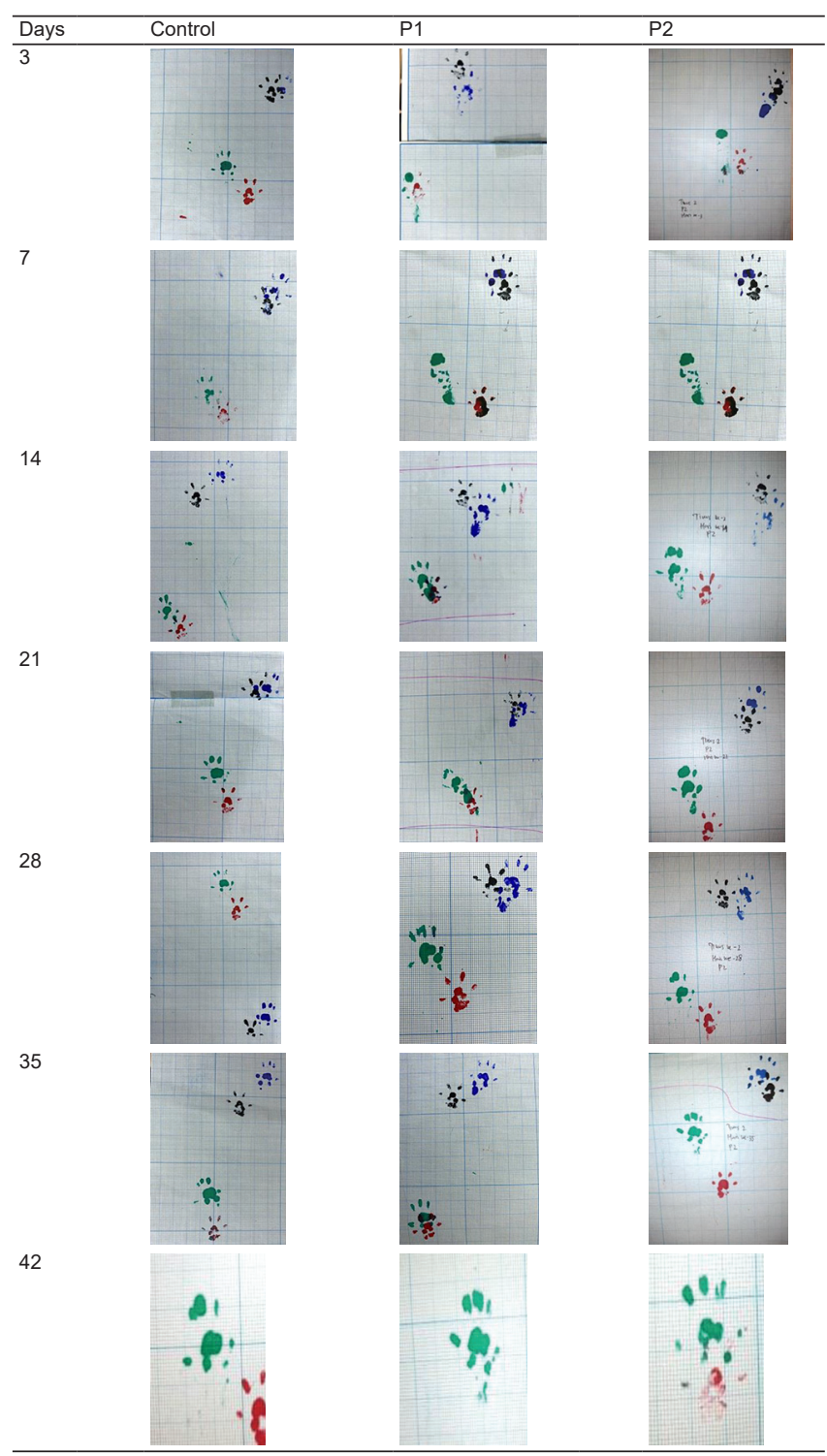

significant change between the $7^{\text {th }}$ and $14^{\text {th }}$ days $(p<$ 0.001 ; paired $t$-test) in the $\mathrm{P} 1$ treatment. The average change in SFI scores on days 7 and 4 was from -144 to 34. This indicates that there was an improvement in the sciatic nerve on day 14 . These data are also supported by footprint changes for the left hindfoot data (Table 2). The change in the footprint showed that on the $14^{\text {th }}$ day, the footprint between the fingers had begun to tread and opened. Moreover, this result indicated that the sciatic nerve was starting to improve after the injury.

This result indicates that the improvement in gait for the aerobic treatment group is better than without the aerobic treatment group. Sciatic nerve repair can be characterized by an increasingly normal footprint. The start of improvement in the sciatic nerve was shown on day 14. However, the visible results of the footprint do not seem to show a perfect improvement. This can be proven by the space between the fingers which begins to open, but the hindlimbs are still treading so that the PL value is still long. The improvement of the sciatic nerve was getting better after day 14-day 42 for the whole group. This is shown in the results that were not significantly different from the control for all groups on day 28-day 42. In addition, the improvement of the sciatic nerve is also shown in Table 1 footprint on the $28^{\text {th }}$ day to the $42^{\text {nd }}$ day of the treated leg showing normal results. The physical activity used in this study was aerobic at low intensity. This aerobic treatment can induce the production of neurotrophic synthesis factors that stimulate nerve growth. Low-intensity aerobics can be used as a useful means of stimulating the growth and regeneration of peripheral axons. Several neurotrophic factors produced by Schwann cells can exert neurotrophic effects on the target. Growth factors that have been identified include nerve growth factor (NGF) and brain-derived neurotrophic factor $[10,11]$.

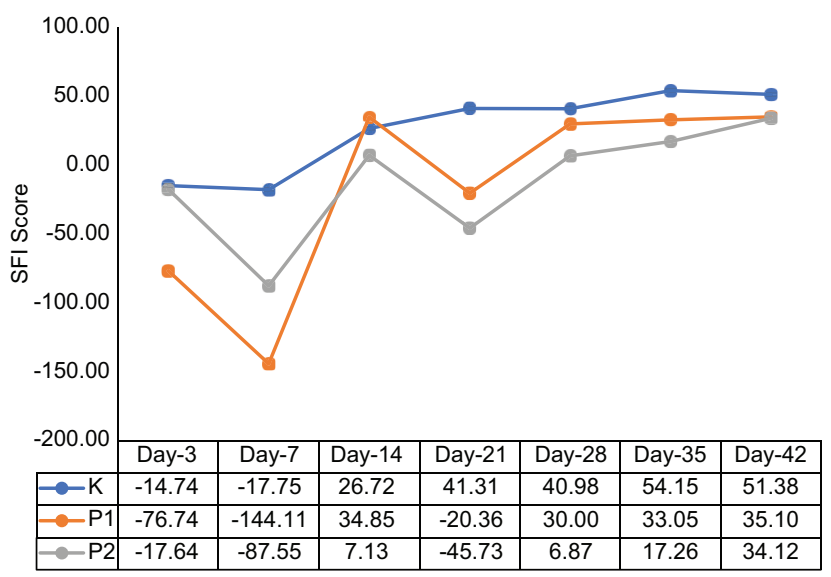

Figure 2: SFI value for each treatment on day 3 to day 42

Apart from gait analysis and evaluation with SFI, indicators of nerve regeneration can also be performed through histological analysis and IHC [27], [28]. Representative staining using histological stain using $\mathrm{HE}$ and IHC with GAP 43 and $\mathrm{S} 100$ is shown in Figure 3

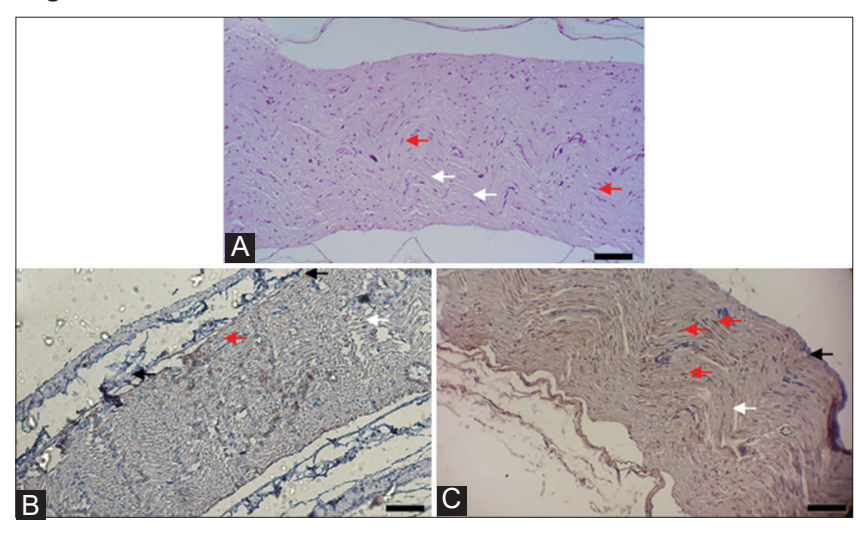

Figure 3: Preparation of longitudinal section of the sciatic nerve after injury with Hematoxylin-Eosin (HE) dye. Immunohistochemistry (IHC) S100 (A) and IHC GAP 43 (B). Nerve fibers consist of axon and myelin sheet (white arrows), perineurium (black arrows), and

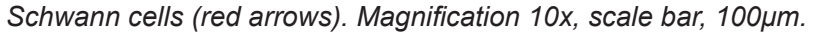

HE staining allows identifying the presence of Schwann cells, perineurium, and nerve fibers consisting of axons and myelin sheets. The hallmark of Schwann cells treated with HE dye is to have a 
Table 2: Footprint changes in treated legs for left hind foot

Day 3 Day 7 Day 21

dark core (purple) because the cell nucleus is acidic, so it will bind to an alkaline color (hematoxylin), while the part around the nucleus is lighter in color (pink) due to the cytoplasm binding an acidic color (eosin). The function of Schwann cells is to produce myelin and wrap around axons. In addition, Schwann cells are also important in the regeneration of nerve cells damaged by injury because they function to regrow axons so that these Schwann cells can be used as one of the parameters in the repair of the sciatic nerve after the treatment of the injury. When an injury occurs, it causes the myelin to degrade at the site of injury. In addition, there is also migration of Schwann cells that function as a bridge at the site of injury and are referred to as growth cones in nerve regeneration. This indicates that the increasing number of optimal Schwann cells in the sciatic nerve allows for maximum nerve repair [29]. Representative expressions of $\mathrm{S} 100$ and GAP43 proteins in the sciatic nerve are shown in brown because of the use of the DAB chromogen. A positive $\mathrm{IHC}$ result will give a brown color, while a negative one will give a blue color. IHC S100 and GAP 43 staining can also be used to analyze neuronal regeneration through Schwann cell analysis. Schwann cells that gave positive expression on IHC S100 and GAP43 staining were indicated by the presence of brown color in the nucleus.

\section{Conclusion}

The improvement of walking function and nerve function in sciatic nerve injury model rats occurred on day 14 , after giving aerobic treatment with low-intensity aerobics to sciatic nerve injury model rats. This is due to the effect of physical exercise on the injured sciatic nerve that was evaluated with SFI.

\section{References}

1. Konstantinou K, Dunn KM. Sciatica: Review of epidemiological studies and prevalence estimates. Spine (Phila $\mathrm{Pa}$ 1976). 2008;33:2464-72. https://doi.org/10.1097/ BRS.0b013e318183a4a2

PMid:18923325

2. Weber $\mathrm{H}$, Holme I, Amlie $\mathrm{E}$. The natural course of acute sciatica with nerve root symptoms in a double-blind placebo-controlled trial evaluating the effect of piroxicam. Spine (Phila Pa1976). 1993;18(11):1433-8.

PMid:8235813

3. Luis RV, Emiliano NV, Juan ES, Gustavo G. Lumbar disc herniated. Rev Bras Ortop J. 2010;45(1):17-22.

4. Canu MH, Garnier C, Lepoutre FX, Falempin M. A 3D analysis of hindlimb motion during treadmill locomotion in rats after a 14-day episode of simulated microgravity. Behav Brain Res. 2005;157(2):309-21. https://doi.org/10.1016/j.bbr.2004.07.009 PMid:15639182

5. Bareyre FM, Kerschensteiner M, Raineteau O, Mettenleiter TC Weinmann O, Schwalb ME. The injured spinal cord spontaneously forms a new intraspinal circuit in adult rats. Nat Neurosci. 2009;7:269-77.

6. Campbell WW. Evaluation and management of peripheral nerve injury. Clin Neurophysiol. 2008;119(9):1951-65. http://doi. org/10.1016/j.clinph.2008.03.018

PMid:18482862

7. Lakshmi R, Aravindaswami P. A review of etiology pathogenesis, treatment of sciatica. Int J Sci Res. 2018;7(1):1477.

8. Frymoyer J. Lumbar disc disease: Epidemiology. Instr Course Lect. 1992;41:217-23.

PMid:1534104

9. Frymoyer JW. Back pain and sciatica. $N$ Engl J Med 1988;318(5):291-300. http://doi.org/10.1056/ NEJM198802043180506

PMid:2961994

10. English AW, Wilhelm JC, Sabatier MJ. Enhancing recovery from peripheral nerve injury using treadmill training. Ann Anat 2011;193(4):354-61. http://doi.org/10.1016/j.aanat.2011.02.013 PMid:21498059

11. de Ruiter GC, Spinner RJ, Verhaagen J., Maless MJ. Misdirection 
and guidance of regenerating axons after experimental nerve injury and repair. J Neurosurg. 2014;120(2):493-501. http://doi. org/10.3171/2013.8.JNS122300

PMid:24116727

12. Scheib J, Hoke A. Advances in peripheral nerve regeneration. Nat Rev Neurol. 2013;9(12):668-76. http://doi.org/10.1038/ nrneurol.2013.227

PMid:24217518

13. Molteni R, Zheng JQ, Ying Z, Gomez-Pinilla F, Twiss JL. Voluntary exercise increases axonal regeneration from sensory neurons. Proc Natl Acad Sci U S A. 2004;101:8473-8. http://doi. org/10.1073/pnas.0401443101

PMid: 15159540

14. Dewi AC, Kurniawan SN, Husna M, Rahayu M. Regenerasi saraf perifer. Neurona. 2014;32(1):60-7.

15. Rui J, Runge MB, Spinner RJ, Yaszemski MJ, Windebank AJ, Wang $\mathrm{H}$. Gait cycle analysis parameters sensitive for functional evaluation of peripheral nerve recovery in rat hind limbs. Ann Plast Surg. 2014;73:405-11. http://doi.org/10.1097/ SAP. 0000000000000008 PMid:24317246

16. de Medinaceli L, Freed WJ, Wyatt RJ. An index of the functional condition of rat sciatic nerve based on measurements made from walking tracks. Exp Neurol. 1982;77:634-43. http://doi. org/10.1016/0014-4886(82)90234-5 PMid:7117467

17. Tajino J, Kuroki H. Three-dimensional motion analysis for comprehensive understanding of gait characteristics after sciatic nerve lesion in rodents. Sci Rep. 2018;8:13585.

18. De Sá JM, Mazzer N, Barbieri CH, Barreira AA. The end-toside peripheral nerve repair Functional and morphometric study using the peroneal nerve of rats. J Neurosci Methods. 2004;136(1):45-53. http://doi.org/10.1016/j.jneumeth.2003.12.018 PMid:15126044

19. De Medinaceli L, Derenzo E, Wyatt RJ. Rat sciatic functional index data management system with digitized input. Comput Biomed Res. 1984;17:185-92.

20. Varejão AS, Melo-Pinto P, Meek MF, Filipe VM, Bulas-Cruz J. Methods for the experimental functional assessment of rat sciatic nerve regeneration. Neurol Res. 2004;26(2):186-94. http://doi.org/10.1179/016164104225013833

\section{PMid: 15072638}

21. Shenaq JM, Shenaq SM, Spira M. Reliability of sciatic function index in assessing nerve regeneration across a $1 \mathrm{~cm}$ gap. Microsurgery. 1989;10(3):214-9. http://doi.org/10.1002/ micr.1920100315

\section{PMid:2796717}

22. Bain JR, Mackinnon SE, Hunter DA. Functional evaluation of complete sciatic, peroneal, and posterior tibial nerve lesions in the rat. Plast Reconstr Surg. 1989;83(1):129-38. http://doi. org/10.1097/00006534-198901000-00024 PMid:2909054

23. Zimmer DB, Eubanks JO, Ramakrishnan D, Criscitiello MF Evolution of the $\mathrm{S} 100$ family of calcium sensor proteins. Cell Calcium. 2012;53(3):170-9. https://doi.org/10.1016/j. ceca.2012.11.006 PMid:23246155

24. Bresnick AR. S100 proteins as therapeutic targets. Biophys Rev. 2018;10:1617-29. https://doi.org/10.1007/s12551-018-0471-y PMid:30382555

25. Park JS, Hoke A. Treadmill exercise induced functional recovery after peripheral nerve repair is associated with increased levels of neurotrophic factors. PLoS One. 2014;9(3):e90245. https:// doi.org/10.1371/journal.pone.0090245 PMid:24618564

26. Sarikcioglu L, Demirel BM. Walking track analysis: An assessment method for functional recovery after sciatic nerve Injury in the rat. Folia Morphol. 2008;68(1):1-7. PMid:19384823

27. Breshah MN, Sadakah AA, Eldrieny EA, Saad KA. Functiona and histological evaluation of rat sciatic nerve anastomosis using cyanoacrylate and fibrin glue. Tanta Dental J. 2013;10:67e-74.

28. Karatman M, Tuncel A, Sheidaei S, Senol MG, Karabulut MH, Deveci I, et al. Amniotinc membrane covering for facial nerve repair. Neural Regen Res. 2013;8(11):975-82. https://doi. org/10.3969/j.issn.1673-5374.2013.11.002 PMid:25206390

29. Anton ES, Weskamp G, Reichardt LF, Matthew WD. Nerve growth factor and its low-affinity receptor promote Schwann cell migration. Proc Natl Acad Sci. 1994;91(7):2795-9. https://doi. org/10.1073/pnas.91.7.2795

PMid:8146193

Author Query???

AQ5: Kindly mention part label $\mathrm{C}$ in figure 3. 